\title{
EL CUERPO EN LA PRODUCCIÓN CULTURAL DE HIJOS E HIJOS
}

\author{
Teresa Basile \\ Universidad Nacional de La Plata \\ terebasile@yahoo.com
}

Resumen: Frente a una, aunque breve, potente tradición en los modos de representar el cuerpo del "desaparecido" ¿cuál es el aporte peculiar de HIJOS? Focalizando en el análisis de Aparecida (2015) de Marta Dillon, proponemos explorar ciertas representaciones del cuerpo del desaparecido del padre o de la madre articuladas por los HIJOS en sus producciones culturales: desde el rostro hasta el cuerpo, desde el cuerpo desaparecido hasta el cuerpo reaparecido, desde el fantasma hasta los huesos, desde el cadáver hasta el resucitado. Se trata de un recorrido por ciertas escenas claves, tales como los montajes con fotografías de los padres en "Arqueología de la ausencia” (19992001) de Lucila Quieto, la figura de la madre en algunos relatos publicados en 76 (2008) de Félix Bruzzone, que van a dar lugar a dos relatos y dos diversas políticas de la memoria: el cuerpo inabordable, mudo e irrepresentable, y el cuerpo recuperado y resucitado.

Palabras Claves: Literatura argentinaLiteratura de HIJOS- Literatura y Memoria

\begin{abstract}
Within a powerful, though brief, tradition of different ways of representing the "missing" body, which is the singular contribution of HIJOS? We focus on the analysis of Aparecida (2015) by Marta Dillon and explore certain representations of the missing parent's body that HIJOS articulate in their cultural productions: form the face to the body, from the disappeared body to the appeared one, form the ghost to the bones, from the corpse to the resuscitated. The itinerary moves into particular scenes, such as the parent's photography montage in "Arqueología de la ausencia" (19992001) by Lucila Quieto or the figure of the mother in some stories of 76 (2008) by Féliz Bruzzone; scenes which give place to two narrations and two politics of memory: the body, mute and irrepresentable, and the recovered body and resuscitated.
\end{abstract}

Keywords: Argentine literatureHIJOS literature- memory and literature 
Su cuerpo dejará, no su cuidado; Serán ceniza, mas tendrá sentido; Polvo serán, mas polvo enamorado. Amor constante, más allá de la muerte Francisco de Quevedo

Porque donde unas cuencas vacías amanezcan ella pondrá dos piedras de futura mirada y hará que nuevos brazos y nuevas piernas crezcan en la carne talada Para la libertad Joan Manuel Serrat

Proponemos analizar ciertas representaciones del cuerpo del desaparecido del padre o de la madre exploradas por los HIJOS en sus producciones culturales: desde el rostro hasta el cuerpo, desde el cuerpo desaparecido hasta el cuerpo reaparecido, desde el fantasma hasta los huesos, desde el cadáver hasta el resucitado. Se trata de un recorrido por ciertas escenas claves, tales como los montajes con fotografías de los padres en "Arqueología de la ausencia" (1999-2001) de Lucila Quieto, la figura de la madre en algunos relatos publicados en 76 (2008) de Félix Bruzzone, y Aparecida (2015) de Marta Dillon, entre otras propuestas. Frente a una, aunque breve, potente tradición en los modos de representar el cuerpo del “desaparecido” ¿cuál es el aporte peculiar de HIJOS? 1

\footnotetext{
${ }^{1}$ Se utilizarán diversos términos para nombrar a la "segunda generación": "H.I.J.O.S." (Hijos por la Identidad y la Justicia contra el Olvido y el Silencio) con puntos apunta a la organización de derechos humanos de un modo general, es decir, sin establecer diferencias entre las diversas ramas; "HIJOS" alude a la generación como una instancia que va más allá de sus vías de institucionalización pero que exhibe lazos de pertenencia a partir de diversas experiencias compartidas -aunque carezcan de padres desaparecidos-; y finalmente "hijos" refiere al lazo familiar.
} 
La foto en blanco y negro tipo carnet y, poco después, la silueta, constituyen las primeras formas en que se representa al desaparecido. Ludmila da Silva Catela (2012), entre otros, recorre este primer y decisivo tramo que se inicia cuando los familiares comenzaron a buscar a sus deudos, yendo con la foto del rostro a las comisarías, a encuentros con liberados de los Centros clandestinos de detención, al exilio, a instituciones de derechos humanos, pasando las fotos de mano en mano para ver si se los reconocía. Luego, con el retorno a la democracia, esas fotos fueron adjuntadas a las listas y a las fichas de desaparecidos confeccionadas por diversos organismos de Derechos Humanos para finalmente construir el archivo de la CONADEP. Asimismo, ocuparon un lugar central en las marchas y rondas de las Madres de Plaza de Mayo y de otros organismos, siendo fotocopiadas y colocadas como pancartas, o estampadas en remeras o en la bandera argentina, creando un fuerte referente icónico para la denuncia, tanto en el contexto nacional como internacional (Catela, 2012). ${ }^{2}$

Quisiera detenerme en la peculiaridad de representar el cuerpo desaparecido a través de una pequeña foto en blanco y negro tipo $4 \times 4$, sacada del documento de identidad, del

${ }^{2}$ Da Silva Catela (2012) no se detiene sólo en el empleo de la fotografía tipo carnet en las búsquedas de los desaparecidos y en las denuncias de las marchas de las Madres de Plaza de Mayo u otros organismos, sino que asimismo aborda la presencia de la fotografía en la intimidad del hogar en donde ocupa un lugar diferencial respecto a las fotos de otros muertos, interpreta el potente significado de la fotografía sobre el cuerpo de las Madres como una vía para reforzar el vínculo y la protección familiar, describe las derivas de la fotografía en otras prácticas de la memoria como muestras, folletos, libros, murales entre las que analiza la sala "Vidas para ser contadas" del Archivo Provincial de la Memoria de Córdoba y, finalmente, señala el uso de la fotografía en el interior de los Centros clandestinos de detención para controlar y reprimir. 
carnet de un club, de una biblioteca, de un partido político, o de una universidad (incluso cuando la foto era de un álbum familiar se la recortaba hasta adquirir la factura de la foto carnet), que facilitaba el reconocimiento (y la denuncia) desde una doble modalidad. Por un lado, focaliza en una identidad de tipo civil que afirma la existencia del ciudadano y su registro por parte del Estado. Enarbolarla constituye una interpelación al mismo Estado en su capacidad de otorgar un Documento Nacional de Identidad cuya validez luego sustrae ilegalmente por medio del secuestro y del asesinato clandestinos. Por el otro, esa identidad se articula a través de una metonimia que hace del rostro el signo identitario de un ser humano particular a través del reconocimiento de las facciones, pero allí no está ni la biografía ni la historia ni las señas particulares, afectos, tendencias culturales que definen la identidad individual $y$ personal, ya que estas marcas perturbarían el acto de identificación y denuncia del desaparecido. Si bien en este tipo de foto no hay anonimato, se presenta cierta borradura de todo aquello que enturbie el pronto reconocimiento en estas fotos austeras, ascéticas, limpias, que vienen a coincidir con el carácter de "víctima" empleado en los primeros tiempos de las políticas de la memoria tal como se advierte en el Nunca Más y en los Juicios a las Juntas (Cueto Rúa, 2008).

El Siluetazo, en cambio, sí exhibe y trabaja sobre el cuerpo más que sobre el rostro -tal como analizan los autores reunidos en la compilación de Longoni y Bruzzone (2008). Fue una de las tempranas prácticas político-artísticas, cuyo inicio suele situarse en la III Marcha de la Resistencia convocada por las Madres de Plaza de Mayo el 21 de septiembre de 1983, a 
iniciativa de tres artistas visuales, Rodolfo Aguerreberry, Julio Flores y Guillermo Kexel, y que luego se propagó y popularizó (Longoni y Bruzzone, 2008, p. 7). Los manifestantes colocan sus propios cuerpos para el dibujo de la silueta, que traza la forma vacía de un cuerpo a escala natural sobre gran cantidad de papeles para luego pegar en los muros, e invadir con ella la ciudad. Apuesta a representar la compleja índole del desaparecido a través de "la presencia de la ausencia" que la silueta suscita, y a interpelar tanto a las instituciones del Estado con la demanda de justicia, como a la conciencia ciudadana para que no olvide. ${ }^{3}$ Ya no se trata de la búsqueda a través de la foto, sino de una práctica política que contiene un condimento "artístico" y se desarrolla en el espacio público. Trabaja con una imagen sin identidad individual para despertar una conexión de solidaridad con el público, bajo el presupuesto de que a cualquiera le pudo haber sucedido ${ }^{4}$. Es, entonces, un cuerpo-víctima vacío, colectivo, anónimo, que apunta -por un lado- a la cantidad y masividad extrema y agobiante de las víctimas producto de un plan sistemático, y que -por el otro- insta a la identificación con la víctima por

\footnotetext{
${ }^{3}$ Esta práctica promovió otras similares, tales como las reinvenciones por parte del GAC (Grupo de Arte Callejero) y de Etcétera, ambos emparentados con la emergencia de H.I.J.O.S. a mediados de los noventa, quienes renovaron con el Escrache las prácticas políticas callejeras de los movimientos de Derechos Humanos. GAC es quien se ocupa de hacer la gráfica de los escraches y los llamados "Blancos móviles" (2004) aparecen como una reactualización del Siluetazo: en este caso en la silueta se dibuja un tiro al blanco y, en algunas ocasiones, se añade la frase "Seguimos siendo blanco de...". Por su parte, Etcétera realizó performances teatrales con grandes muñecos, máscaras o disfraces en las que representan escenas de represores, como actos tortura, apropiación de niños, etc. (Longoni y Bruzzone, 2008, pp. 5-60).

4 Cfr.: el acto de poner el cuerpo, de "ocupar el lugar del ausente es aceptar que cualquiera de los allí presentes podría haber desaparecido" (Longoni y Bruzzone, 2008, p. 32).
}

Nº7. Primer semestre de 2017 
parte del público. Se trata de una figura abierta a futuras proyecciones, a los nuevos desaparecidos. El tamaño natural de las siluetas es una focalización en el cuerpo, que procura invisibilizar toda mediación simbólica, aquí no hay metonimia de la parte por el todo, sino un cuerpo representado desde un formato "realista", obtenido a partir de la presencia de otro cuerpo que se conecta desde el anonimato. ${ }^{5}$ En principio la propuesta del Siluetazo consistía en una personalización de las víctimas pero las Madres señalaron el inconveniente de que las listas de los desaparecidos eran incompletas $(29)^{6}$ y por ello la silueta anónima también nos habla de las políticas de desinformación, de la negativa de las Fuerzas Armadas por entregar listas y datos sobre los desaparecidos. La idea misma de desaparecido -de la ausencia intencional (Grüner, 2008)adquiere consistencia en ese borramiento de las marcas personales e identitarias que se articula en la silueta blanca. Los participantes solían individualizar espontáneamente estas siluetas colocándoles marcas de sus propios desaparecidos, como señas particulares o los nombres y las fechas de la desaparición. El público, que al día siguiente veía las siluetas pegadas en las paredes, se sentía mirado por esas figuras que parecían reclamar un lugar en la memoria.

Para señalar la apuesta a una memoria activa frente a las cristalizaciones del bronce, Estela Schindel (2008) explora el

\footnotetext{
5 A su vez, el acto de encarnar ese cuerpo por parte del manifestante es darle una corporeidad y una vida, aunque sea efímera, al desaparecido, haciendo de la silueta una "huella que respira", "en cada silueta revivía un desaparecido", según las palabras de Nora Cortiñas (Longoni y Bruzzone, 2008, pp. 32-33).

${ }^{6}$ En el segundo Siluetazo no se mantuvo el anonimato, sino que se comenzó a incluir nombres de los desaparecidos, sacados de listas
} 
carácter performativo del Siluetazo y de otras prácticas políticoartísticas, repasando diversas instancias como las marchas de las Madres, el empleo de las fotos, los avisos publicados por Página/12, los escraches y el conjunto de esculturas del Parque de la Memoria. Se suele entender el Siluetazo como una concreción de la consigna "Aparición con vida" esgrimida por las Madres desde 1980 -primero formulada ante la sospecha de que hubiera desaparecidos aún con vida ("con vida los llevaron, con vida los queremos"), aunque luego de conocer su destino trágico también fue sostenida por su dimensión ética e incluso redentora. En esta línea, Gustavo Buntinx (2008) advierte cierta esperanza de vida alentada por las Madres. De este modo el Siluetazo va desde la ausencia del desaparecido hasta la esperanza de su aparición. También las Madres insisten en el carácter vital que deben exhibir las siluetas, rechazando la posibilidad de pegarlas en el piso o dibujarlas acostadas como si se tratara de muertos y prefieren presentarlas erguidas y de pie (Longoni y Bruzzone, 2008, pp. 34-35). ${ }^{7}$

¿Cuál es el aporte que la generación de HIJOS introduce a mediados de los noventa frente a esta primera representación del cuerpo a través de la foto carnet que perfila la identidad civil de la víctima sin señas particulares y de la silueta que dibuja la presencia del cuerpo vacío del desaparecido? Para esta segunda generación ya no se trata únicamente de articular una

\footnotetext{
${ }^{7}$ No obstante, y en contraposición a las siluetas blancas y erguidas, también en esta III Marcha aparecen siluetas negras inscriptas sobre el pavimento bajo la consigna "Toda la verdad" que formulaba una demanda de investigación y la denuncia a los responsables de los asesinatos. Aluden al procedimiento policial de dibujar la silueta del abatido, y también eran leídas como "todos los desaparecidos están muertos" (Longoni y Bruzzone, 2008, pp. 35-36).
} 
demanda pública de verdad y justicia, sino de capturar la historia particular de los padres en tanto padres, militantes y parejas, con sus gustos, costumbres, con sus cuerpos vestidos y sexuados, con sus deseos, sueños, apuestas y temores, en la vida cotidiana, en el interior de la casa, así como en el mitín político, oyendo música o comiendo un mondongo, como prefiere Mariano Pujadas: "No me interesa saber si él fue un héroe o un villano. Si mató o no mató, porque hay cosas que tienen que ver con el contexto histórico. Hace poco me enteré de que a mi viejo le gustaba el mondongo. Es una pelotudez, pero me ayuda a saber quién era. Me gustaría saber si jugaba bien al fútbol o era un cagón como yo" (Arenes y Pikielny, 2016, p. 235).

Debemos recordar que quienes crearon H.I.J.O.S. alrededor de 1995 desplazaron la mirada anclada en la dictadura hacia el período anterior del quinquenio 1970-1975 -que sólo era mencionado por los militares- y rescataron la militancia de los padres (idealistas, revolucionarios, soñadores, guerrilleros) frente a las imágenes de "terroristas", "subversivos" y "extremistas" enhebrada por los militares o la de "víctimas inocentes" que roturaron los organismos de Derechos Humanos (Cueto Rúa, 2008). Junto con este recobro de la agencia histórica de los padres, también indagaron en su universo privado, personal y familiar desde y con la mirada de hijos que en muchos casos desconocían o recordaban a medias a sus progenitores. Esta pulsión de conocimiento es característica de los hijos, en cambio -es obvio decirlo- no está en las madres. Mientras las Madres sostienen haber sido paridas por sus hijos en tanto ellas, como en un segundo 
nacimiento, recondujeron sus vidas a partir de las pérdidas, los HIJOS afirman que han parido a sus padres al devolverles su identidad y su subjetividad, aquellas que el Estado les sustrajo (Amado, 2003, p. 142).

Desde el inicio de la producción cultural de HIJOS podemos encontrar dos perspectivas de acercamiento a los padres desaparecidos, que no son excluyentes y suelen confluir. Por un lado, el cuerpo desaparecido es inabordable, inalcanzable y desconocido, cualquier intento por encontrarlo, descubrirlo o conocerlo resulta una tarea fracasada. Los textos de Félix Bruzzone exploran esta línea. "Unimog" es uno de los relatos de 76 que expone la imposibilidad de dialogar con el padre, de establecer algún tipo de vínculo que no sea una decepción, en el intento del protagonista por averiguar el destino final del padre haciendo un viaje hacia Córdoba. Una serie de inconvenientes y desperfectos del camión le impiden llegar a destino y desatan la ira de Mota, quien ahora interpela al Unimog como si fuera su progenitor, sin recibir respuesta: "no podía decir nada porque sobre todo eso nadie podía decir nada" (p. 43). La lluvia incluso le impide matarlo ya que apaga el fuego (la imposibilidad del parricidio), una lluvia que va a formar las lagunas (de la memoria). Los padres son testigos mudos en los cuentos de Bruzzone y no hay ni diálogos

\footnotetext{
${ }^{8}$ No está de más recordar que Félix Bruzzone casi no conoció a sus padres. Hijo de Marcela Bruzzone Moretti y de Félix Roque Giménez, militantes del Partido Revolucionario de los Trabajadores (PRT) y del Ejército Revolucionario del Pueblo (ERP). Su madre fue secuestrada el 23 de noviembre de 1976 y llevada al Centro Clandestino de Detención (CCD) "El Campito", en Campo de Mayo. Su padre fue secuestrado el 15 de marzo de 1976 en Córdoba, en la vía pública, y permaneció en cautiverio en el CCD "La Perla", en Campo de La Ribera, Provincia de Córdoba. En cambio, la madre de Marta Dillon, como veremos más adelante, desapareció cuando ella tenía 9 años, de allí la presencia de múltiples recuerdos en común.
} 
posibles ni respuestas, ni fotos que les revelen datos o los acerquen a ellos. Tanto el rostro como el cuerpo resultan fragmentados, indescifrables y travestidos, como la estampa de la madre que el protagonista niño proyecta en una cara de la revista Play Boy desdibujada por el agua y luego destrozada bajo las ruedas del auto ("Una casa en la playa"). Las figuras de las travestis, tanto en los cuentos de 76 (2008) como en su novela Los topos (2008), constituyen metáforas de la dificultad de dar un rostro al desaparecido, constantemente imaginado de diversos modos. En "Chica oxidada" dice el narrador sobre su madre: "como no sé bien cómo era, podía ser muchas cosas [...] formas difíciles de precisar" (p. 83). ${ }^{9}$

Por otro lado, surgen propuestas que intentan ocupar este vacío (sin negarlo) con datos, escenas, noticias sobre los padres, a través de la búsqueda y averiguación, la conversación y el diálogo con los compañeros de militancia, con los familiares, con los vecinos, a través de fotos, de cartas, de rastros dejados por ellos. Un caso paradigmático es la temprana propuesta de Lucila Quieto en "Arqueología de la ausencia -1999-2001", donde a través de montajes fotográficos proyecta imposibles encuentros con los progenitores en los que comparten momentos de la vida. El cuerpo en estas fotos es un claro ejemplo de la mirada de los hijos que intenta reponer los datos personales, los gestos, el color, el escenario que los rodea, el momento en que se tomó la foto. Estos montajes exhiben la necesidad de tocar a los padres, de acariciarlos, de festejar con ellos, de participar y compartir

9 Analizo con más detenimiento esta presencia del travestismo en los textos de Bruzzone en Basile, 2016. 
momentos, como si el acontecimiento de la desaparición pudiera colocarse por un instante a un costado para dejar lugar a la alegría y al festejo, al disfrute que no estuvo. El montaje es casi un acto de magia, se asemeja al juego de la copa u oüija con el que se procura hablar con los espíritus de los muertos, y en ocasiones la escritura o el arte aparece como un "médium" que hace hablar a los muertos. ${ }^{10}$ Pero acá no hay espíritus sino un montaje de imágenes en las que los cuerpos ocupan un lugar central. Cierta voluntad de resucitar a los padres se hace evidente y es este acto de resurrección la escena que me interesa destacar como una apuesta central en la producción cultural de HIJOS. Una recuperación ejercida en el espacio de los afectos y vínculos filiales, y que resulta paralela al rescate que asimismo hacen de los ideales políticos, visible en la consigna "Nacimos en su lucha, viven en la nuestra". La crítica se ha detenido extensamente en los procesos del duelo, pero mucho menos en el acto de "volver a la vida" a los padres.

En Aparecida de Marta Dilllon esta pulsión vital de resucitar a la madre se convierte en un acto central que emerge cuando "aparecen" sus huesos. ${ }^{11}$ La autora aborda su propia experiencia centrada en el encuentro de los huesos de su madre, Marta Taboada, por parte de los antropólogos forenses,

${ }^{10}$ En Aparecida, la narradora comenta "Maco nos incitaba a que escribiéramos esas historias (...) Al fin y al cabo son como médiums que hacen hablar a los muertos" (p. 41), así como también comenta la costumbre en las reuniones de HIJOS de convocar a los espíritus de los padres en el tablero ouija (p. 75).

${ }^{11}$ En realidad, cuando ella ingresa en H.I.J.O.S. y toma contacto con sus compañeros es el primer momento en que sueña un encuentro con su madre como una experiencia vital, como un "sueño vívido", y vuelve a dar vida a su madre "Por esos días tuve el primer sueño vívido con mi madre. Ella me abría los brazos y yo corría a abrazarla, sentía su pelo rubio contra mi cara, el olor de su pecho, su temperatura. No fue triste despertarme, había estado con ella otra vez, por primera vez" (p. 48). 
su "aparición" remite al último tramo de los avatares de la búsqueda que los hijos emprenden, abriendo la posibilidad de efectuar el duelo y poner punto final a ese doloroso recorrido. En esta línea, el texto permite explorar la experiencia de la "aparición" de los huesos, la narradora lo dice claramente "Mi madre estaba desaparecida. Ya no" (p. 46), ahora deja de ser un fantasma ("el latido fantasma del corazón de mi madre se detenía", p. 162), lo que vertebra una serie de motivos, problemas, tópicos nuevos en torno al velatorio, el funeral, el entierro y el duelo, dispara una serie de reflexiones sobre los huesos, el cadáver y el cuerpo, y constituye un punto final a la espera, a la búsqueda, a la averiguación -al "rescoldo" sobre el que siempre "soplamos" para que transmita la voz, la vista y la vida del desaparecido (p. 48)-, y a esa fantasía sobre la posible aparición con vida que chispea en todo deudo de un desaparecido, entre otras cuestiones. También modifica cierta temporalidad de los HIJOS de desaparecidos al detener la espera hacia el futuro y regresar al pasado en que aconteció la muerte como si se comprimiera el tiempo ("la noticia tenía la capacidad de comprimir el tiempo, como si se pudieran aplastar más de treinta años entre dos palmas, como a un mosquito", p. 47).

Pero lo que en este relato (me) interesa no es la posibilidad del duelo, en cierta medida esperable, sino otros dos puntos: las dificultades, trampas y pérdidas que supone el duelo por un lado y, por el otro, el acto de devolverle vida a los huesos encontrados, una suerte de resurrección carnal de la madre que atañe no sólo a su alma, a su historia, a su identidad sino a su 
cuerpo recordado desde la "memoria corporal" guardada por la hija.

Respecto a la posibilidad del duelo inaugurado por el hallazgo de los huesos, éste resulta un proceso atravesado por pérdidas y temores ("No estaba lista. No quería perder a mi santita de ojos azules y pelo al viento", p. 73). En cambio, la melancolía ${ }^{12}$ sostiene el vínculo particular con la madre, y lejos de presentarse como un cuadro patológico, es el espacio amoroso de encuentro con ella, donde acontecen momentos de iluminación y de epifanía: "Yo quedé prendada de esa bóveda de luz sobre la línea del tiempo que dejó la ausencia de mi madre, volviendo a los hechos, las palabras, los gestos, los silencios de entonces para siempre iluminados por la violenta siega de su cuerpo" (p. 56). Por ello Marta se resiste a abandonarla: "¿Tendría que extirparme la melancolía como un quiste?” (p. 52).

El duelo suele ser un proceso complejo para los HIJOS ya que, en principio, no cuentan con la muerte de los padres sino con su "desaparición", y como sabemos esta particular condición se caracteriza por la indefinición, el desborde de los conceptos identitarios acuñados, la impertinencia (no pertenencia) categorial. Gabriel Gatti argumenta extensamente

12 En este sentido, las categorías de duelo y melancolía como modos de elaborar las pérdidas en torno a los desaparecidos han organizado ciertos debates en Argentina, marcando grosso modo dos líneas: mientras algunos solicitaron conocer la historia y el destino de las víctimas así como recuperar sus huesos para poder tramitar la herida y realizar el duelo, en cambio, otros se resisten a pensar el duelo en términos de un proceso cerrado que supone la sustitución del objeto perdido por otro (Freud, 1993), por ello es posible advertir la progresiva importancia que la melancolía (en detrimento del duelo) va adquiriendo en estas reflexiones ya que se busca no olvidar a las víctimas. Desarrollo este debate en Amar Sánchez y Basile (2014). 
sobre la dificultad para asir la identidad del desaparecido, tensada entre la ausencia y la presencia en tanto se trata de un sujeto que no se halla ni vivo ni muerto y parecería situarse en una suerte de limbo, en un eterno "estar siendo desaparecido" que no termina de cerrarse; en tanto se trata de un sujeto sin lugar y descolocado del tiempo, desgajado de la comunidad y de la familia, un cuerpo separado del nombre o un nombre sin cuerpo y sin historia, un sujeto sin derechos ni ciudadanía, un "chupado", "borrado", un "vivo-muerto", un espectro, un fantasma (2011, pp. 61-65). Asimismo, Kordon y Edelman señalan que la desaparición implica una presencia-ausencia que se mantiene a lo largo del tiempo e incluso a pesar de conocer la muerte del desaparecido, generando una situación de "duelo prolongado" (2007, pp. 75-76). El duelo, necesario para metabolizar el sufrimiento psíquico provocado por la pérdida y lograr recolocar la libido en otro objeto, se encuentra obstruido por el desconocimiento de lo acontecido y la falta del cadáver, lo que impide realizar el rito funerario.

Finalmente, en Aparecida el duelo se impone no sólo por el hallazgo de los restos de la madre, sino también por la necesidad de colocar su libido en el presente, en su casamiento con Albertina o en las demandas de su pequeño hijo Furio. Como en muchos otros textos, aquí emerge el conflicto entre la búsqueda de los padres y la búsqueda propia ("Me iba a casar en veinte días [...] debería estar ocupándome del aquí y del ahora", p. 53).

Más que la posibilidad del duelo, lo que este texto despliega de un modo imperativo, es todo un ritual de resurrección de la figura materna que atañe no sólo al espíritu y personalidad de 
la madre, sino y, sobre todo, al cuerpo. Se trata de ver a los desaparecidos, como un acto de magia. ${ }^{13}$ En su primera aparición, el cuerpo se hace visible a través del abrazo recordado, añorado e imposible-, un tópico que reaparece continuamente desde el inicio mismo de la novela en la descripción de la foto con su madre, vinculando la memoria corporal de la protagonista con el deseo de devolverla a la vida. ${ }^{14} \mathrm{~A}$ través de un proceso de reconstrucción (resurrección) la narradora va de la desaparición a la aparición, de los huesos al cuerpo, del cadáver a la vida, de los harapos a la ropa (reinventando el tropo de la prosopopeya). Al recordar a compañeros de militancia de la madre, reflexiona "no eran una comparsa de fantasmas sino historias y cuerpos animados, capaces de sufrir, de resistir y de morir, no sólo de desaparecer" (p. 19). Aún en las escenas sobre sus últimos días en cautiverio, la narradora elije momentos que muestran "vital, coqueta y creativa" (p. 25) a la madre, cortando las mangas de la polera porque hacía calor.

Ciertos ejemplos iluminan este proceso de recomposición: ante la necesidad de buscar fotos sobre la dentadura de la madre para los antropólogos forenses, ella exalta su sonrisa "la sonrisa de mi madre es especial, apenas podía cerrar la boca, sus dientes eran tan grandes como pistas de esquí" (p. 26); el cráneo le recuerda la "ceremonia de la toca" que sólo ellas

\footnotetext{
${ }^{13}$ La idea de hacer un audiovisual constituía para la narradora un modo de "saldar mi ansiedad de ver. Porque era eso lo que yo quería, ver ¿Ver qué? A los desaparecidos, qué más, qué magia mayor que esa" (p. 30).

${ }^{14}$ La "caricia" ocupa un lugar simbólico similar al "abrazo", como por ejemplo cuando Marina enreda en los huesos de su padre "un mechón de su pelo para sentir la caricia que nunca había tenido" (p. 42).
} 
compartían (p. 61); frente a los huesos desea vestirlos con las prendas preferidas de su madre, las polleras largas, las túnicas, los jardineros, la campera a rayas, la coqueta ropa interior, los collares y aros, las plataformas "¿Podría alguna tela cubrir sus costillas? (p. 28).$^{15}$ Cuando se topa con el fémur, recuerda las "piernas de gacela" de la madre "largas, bien torneadas, ideales para la minifalda" (p. 58). En lugar de la desintegración del cuerpo acontece la resurrección de la carne, y el acto de vestir el cuerpo hace brotar la vida de los huesos: "La certeza envolviendo ese fémur; envolviendo y devolviendo, una capa tras otra de nervios, sangre, carne, grasa, dermis, epidermis, los pelos, las medias de nylon, la pollera a cuadros de lana y mi cabeza sobre ella" (p. 60). La madre también aparece con su vitalidad intacta en las películas de súper 8 que su hermano le envía, donde "ella" está "viva", en movimiento, junto a su padre y a sus hermanos (p. 173). Hay una apuesta a la materialidad del cuerpo, a sus fluidos, a los actos amorosos y sexuales, a los abrazos maternales y fraternales, a la enfermedad del cuerpo y a su abyección. La propia maternidad de Marta se significa a través del cuerpo, ella se despierta abrazada a su hijo "enredados los dos, piernas, brazos, su respiración (...) mi maternidad es cuerpo a cuerpo" y se muestra a partir del aliento, el sudor, las babas, las sangres, las lagañas, los mocos, las lágrimas, ya que "el lenguaje del amor

15 En varias oportunidades se reflexiona sobre el valor de los huesos, que aun cuando ella los quiere consigo, aun cuando sirven como prueba condenatoria, constituyen restos de una vida, residuos de una existencia, material para los antropólogos: "Material de investigación, series cifradas, objetos que juntan polvo, polvo sobre polvo sin sus deudos, su comunidad, su historia” (p. 30); “¿Qué habían encontrado de ella? ¿Para qué quería yo sus huesos? Porque yo los quería, quería su cuerpo. De huesos empecé a hablar más tarde, frente a la evidencia de unos cuantos palos secos y amarillos, iguales a los de cualquiera" (p. 33). 
no se habla, se inscribe. Esa poesía material es la que aprendí de mi madre" (p. 49). ${ }^{16}$

En las ceremonias funerarias con sus preparativos y en el entierro, esta resurrección de la madre alcanza un punto culminante, transita del espacio íntimo hacia el universo, salta del ámbito privado hacia el público, va del hogar hacia la política y la historia, atraviesa el límite de lo profano para sacralizarse en su última aparición epifánica. ${ }^{17}$ La resurrección se vuelve ritual compartido por la cofradía de las "hermanas" de militancia y en el entierro se despliegan las banderas de H.I.J.O.S. Se pone en escena la potencia libidinal, mágica, utópica característica de cierto sector de la producción de HIJOS, que reactualiza la tradición de las prácticas políticoartísticas de la memoria iniciadas por las Madres en su porfiado reclamo de "aparición con vida". Gustavo Buntinx (2008) destaca esta perspectiva en su análisis de ciertas prácticas "rituales" sobre memoria centradas en los principios de "presencia y vida", del "poder de la utopía y su imaginario libidinal", de tendencias "mesiánicas" que, a través de rituales como las marchas de las Madres y el Siluetazo (poner el cuerpo donde ya no estaba, llenar con vida un vacío), procuran revertir

16 En Aparecida, Marta también dará cuenta no sólo de este aprendizaje a través del cuerpo sino también de las ideas y apuestas revolucionarias de su madre, de las conversaciones que ambas mantenían, del regalo de Mi planta de naranja lima, entre otros canales educativos.

${ }^{17}$ En Aparecida no hay juicio condenatorio ni reclamo a la madre: "aunque yo no pueda enojarme con mi mamá por haber vivido en sus cortos 35 al menos intensamente dos vidas. Una no deja de ser quien es porque tiene hijos" (p. 29). Hay toda una valoración del rol materno, visible tanto en el vínculo de la narradora con su madre como con sus hijos y que se articula en la imagen, presente en la pesadilla, de la madre salvadora que procura resguardar la vida de la hija al costo de la propia "Tengo que salvarla a ella" (p. 77).

No7. Primer semestre de 2017 
las desapariciones gestadas desde el poder y recuperar "para una vida nueva a los seres queridos atrapados en las fronteras fantasmagóricas de la muerte" (p. 259). La resurrección y la insurrección se refuerzan en un mismo acto (p. 260).

Aquella iluminación aurática y epifánica de la madre si bien se vuelca en un marco realista, termina por inscribirse en la matriz del neobarroco latinoamericano, en sus versiones más pop, en los trazos de Néstor Perlongher y Pedro Lemebel, ${ }^{18}$ quienes cruzan la exquisita lengua neobarroca del cubano José Lezama Lima con las fablas más populares y bastardas del neobarroso y del neobarrocho, para interrogar las barbaries de las dictaduras del cono sur. Desde esta matriz estética se exploran escenas en que se cruzan experiencias radicales y opuestas, que exaltan la vida y registran la muerte, ahondando los contrastes de luces y sombras que caracterizan todas las formas del barroco. El festejo del casamiento de Marta y Albertina se encuentra con la doble presencia de la muerte de la madre y de Néstor Kirchner ("el presidente que había reivindicado parte de la generación masacrada", p. 97), que lejos de empalidecer el festejo, profundiza los contrastes: ellas se visten con disfraces mitad bailarinas de Can can, mitad dominatrices "obligando al dolor a aullar de alegría" (p. 96) y Marta se casa "sangrando [...] dejé que el rastro rojo de mi menstruación se mezclara con el vino derramado" (p. 97). El barroco con su bastardía penetra en las tensiones del cuerpo de Marta, enfermo de SIDA, pero atravesado por el éxtasis del deseo, o en ese cuerpo abyecto que despierta en el piso junto a la basura, luego de un funeral que parecía una fiesta, luego del

\footnotetext{
${ }^{18}$ En cierto momento Marta recuerda “Cadáveres” de Néstor Perlongher (p. 141).
} 
vómito en el baño (p. 153), o en el enamoramiento de Marta hacia Liliana Maresca cuando esta se encuentra "en agonía", a punto de morir de SIDA, en una suerte de "muerte bella" (p. 159). Se trata de un cuerpo que parte del dolor para exhibir su esplendor, que se ilumina en la celebración y la fiesta ante la amenaza de la muerte. Es un cuerpo (con sida) de los 90 que se vincula a los cuerpos de la psicodelia de los 60 , atravesados por el sexo, la droga y la revolución. El cuerpo de la madre es también un cuerpo acechado por el peligro y por la muerte ( $p$. 176). Es, entonces, la matriz barroca aquella que mejor sabe explorar la tensión y mezcla entre la palpitación extrema de la vida en la militancia, en las ansias revolucionarias, en la pasión y el arrojo, en el goce del cuerpo, en el éxtasis del deseo, y el acecho de la muerte, los compañeros caídos, la persecución de los militares, el peligro del SIDA, todo lo cual exhibe la precariedad de la vida, simbolizada en el vaso detenido en la foto en un instante antes de caer (p. 180).

Es, además, un barroco en clave popular latinoamericana, cercano al estilo proliferante de las festividades mexicanas, con ingredientes de la cultura villera y cartonera argentinas, ${ }^{19}$ con aportes de las santerías con sus altares llenos de ofrendas, que se multiplicaron hacia fines del siglo a propósito de las muertes

19 La presencia del cartonero en Buenos Aires (continuador del ciruja de principios de siglo) se hizo notable a partir de la crisis económica del 2001 que trajo el desempleo y la pobreza. Se convirtió en un sujeto urbano con una peculiar identidad cartonera, aceptado en gran medida por la sociedad, y que supo reorganizarse en cooperativas mejorando sus condiciones de trabajo. Impulsó la creación de una cultura cartonera cuyo emblema fue la Editorial Eloísa Cartonera (2003). Por su parte, los artistas y diseñadores se apropiaron de cartones, residuos y materiales desechables para crear objetos, hacer instalaciones o intervenciones urbanas, reutilizando la basura para el arte. 
de Gilda y Rodrigo. ${ }^{20}$ Se hace visible en los preparativos del ritual mortuorio, en el que la música, el baile y las risas se combinan con momento de éxtasis sagrado, de "locura", "demencia". ${ }^{21}$ Los restos de la madre son colocados en una caja de cedro laqueada en blanco, una urna que ella y sus amigas van a convertir en una "cuna de oro", en un "alhajero", en un altar, en el que van a ir depositando diversos recuerdos, exvotos, donativos e imágenes: guerrilleras zapatistas, catrinas, santos populares, indios, piedras, un corazón recortado sobre un libro de Corín Tellado, brillantinas, pendientes de ojo de tigre, pastaflora, lanas, pétalos, entre otros (p. 192). Marta se dispone a la última aparición de la madre (tal vez este sentido y no la referencia al encuentro de los huesos constituya el significado y referente del título del libro), a su epifanía "aunque fuera por un segundo (...) iba a estar entre nosotros" (p. 188) - para que su hija pueda "caer de rodillas como una iluminada frente a su presencia incandescente", entrar "en trance" y ver "cómo sobre ella se reflejaba el Universo" (p. 199). ${ }^{22}$

El reencantamiento de la madre adquiere dimensiones políticas, y se vincula asimismo con el reencantamiento de la

\footnotetext{
${ }^{20}$ Las tempranas muertes en accidentes de tránsito de Gilda (1996) y Rodrigo (2000), ídolos populares de la cumbia y del cuarteto, dieron lugar a la construcción de santuarios a la vera de las rutas donde fallecieron, que se convirtieron en lugar de peregrinación para sus seguidores, bajo la consigna de que seguían "estando vivos".

${ }^{21}$ Esta amalgama de religiosidad, sensualidad, éxtasis y locura caracteriza al barroco escultórico del Éxtasis de Santa Teresa de Lorenzo Bernini.

${ }^{22}$ Incluso Marta imagina la posibilidad de cremarla con sus propias manos y a cielo abierto, como un rito también barroco que hace de la religión una experiencia de transformación, de alquimia incandescente y de trance (p. 190).
} 
política que los gobiernos de Néstor Kirchner (2003-2007) y Cristina Fernández de Kirchner (2007-2015) llevaron a cabo desde una propuesta neopopulista (Laclau, 2005), luego del apagón de la militancia durante los gobiernos neoliberales de Carlos Menem. En Aparecida, la autora hace explícito su apoyo y entusiasmo a la era $\mathrm{K}$, tanto respecto a las relecturas de los setenta y a las políticas de derechos humanos, como a las leyes de matrimonio igualitario bajo las cuales se casa con Albertina Carri. También en este texto está presente la perspectiva de una continuidad entre la lucha revolucionaria de los padres y el espacio político abierto por los Kirchner, en el cual los H.I.J.O.S. van a reinscribir su legado. El desaparecido se ha resguardado en una latencia que lo despierta transmutado en otros cuerpos del presente, semilla en espera que recién ahora brota. La urna será primero transportada hasta su casa de Moreno en una cureña hecha con un carro de cartonero y cubierta con una bandera argentina y luego será llevada en un "camión militante" rodeado de las banderas de H.I.J.O.S., Madres y Familiares, agrupaciones políticas, en un entierro que será colectivo y público. Sus compañeros la recuerdan como una "ninfa rubia para siempre, joven y audaz", como la "Evita Montonera" que engalanaba su ataúd. La figura de la "ninfa" remite a cierta tradición argentina en torno a la Evita edificada desde el peronismo revolucionario de izquierda. José Emilio Burucúa (2003b) retoma la imagen de la ninfa, acuñada por Aby Warburg, para señalar un ejemplo de "vuelta a la vida" o "sobrevivencia" (Nacbleben) en la fotografía de Eva Perón con el pelo suelto, joven y sonriente -muy diferente a la imagen oficial- que fue capturada por el juvenilismo revolucionario de 
los 70. Alejandra Oberti (2015) analiza esta reconfiguración que tiende a borrar sus trazos más conservadores, en especial su lealtad a la palabra de Perón y su antifeminismo, para reponer a una Evita Montonera, combatiente, que vuelve para hacer la revolución ("si viviera sería Montonera). Y luego este modelo sirve para el retrato estetizado de la guerrillera hermosa, serena y valiente de la misma época (2015, pp. 93-124). Las fotos elegidas por Marta Dillon para ilustrar la tapa del libro responden certeramente a la "ninfa".

Resulta necesario recolocar, a su vez, esta posibilidad de resurrección en la tradición peronista referida a Eva Perón, escandida por textos seminales como el de Copi (Eva Perón, 1970) donde se afirma "Evita, señores, está más viva que nunca" o por "Evita vive" (1975) de Néstor Perlongher en donde ella desciende del cielo dispuesta a recorrer los bajos fondos como prostituta, reventada y drogadicta para llevar su contención a los nuevos descamisados -sin olvidar el imaginario en torno a la "Evita montonera" ni la predilección que Cristina Fernández de Kirchner mostró por ella (estos ecos aparecen sugeridos en el pronombre "Ella" con el que se nombra a Marta Taboada en ciertas oportunidades). Esta tradición (en parte gay y lesbiana), a su vez provoca el cruce entre la santidad y la abyección, dos marcas que reaparecen en Aparecida.

Frente a la desaparición gestionada por el Estado dictatorial, Aparecida responde con la contundencia de la resurrección de la madre en la militancia de H.I.J.O.S. y en las políticas de Derechos humanos de los gobiernos kirchneristas, a través de una estética que recupera las astillas populares, festivas, 
abyectas y santeras de los neobarrocos latinoamericanos y sus derivas antidictatoriales del Cono Sur. Una renovada inscripción de la pulsión redentorista que Benjamin buscaba en el pasado de la historia para reactualizarla en el presente de la democracia -una apuesta a ciertas políticas de la memoria que en ocasiones alcanza una radicalidad no del todo armonizable con los principios de la democracia. Configura uno de los polos extremo y, a su vez, distante de quienes eligieron el camino de la autocrítica de la izquierda armada.

\section{Referencias Bibliográficas}

Amado, A. (2003). "Herencias, generaciones y duelo en las políticas de la memoria", en Revista Iberoamericana, Vol LXIX, N ${ }^{\circ}$ 202, enero-marzo 2003, pp. 137-153.

Amar Sánchez, A. M. y Basile, T. (2014). "Introducción”. En Amar Sánchez, A. M. y Basile, T. (Eds.). Derrota, melancolía y desarme en la literatura latinoamericana de las últimas décadas (pp. 327-349). Número Especial de la Revista Iberoamericana, Vol. LXXX Abril-Junio 2014 Núm. 247, Instituto Internacional de Literatura Iberoamericana (IILI): Pittsburgh.

Arenes, C. y Pikielny, A. (2016). Hijos de los 7o. Historias de la generación que heredó la tragedia argentina. Buenos Aires: Sudamericana.

Basile, T. (2016). "La orfandad suspendida: la narrativa de Félix Bruzzone", en el dossier Formas de la Memoria II, Revista Celehis. Revista del Centro de Letras Hispanoamericanas, Núm. 32 (2016). Universidad Nacional de Mar del Plata: pp. 141-169.

Buntinx, G. (2008). "Desapariciones forzadas/Resurrecciones míticas (Fragmentos)", en Longoni, A. y G. A. Bruzzone 
(comp.) (2008). El Siluetazo. Buenos Aires: Adriana Hidalgo editora, pp. 253-284.

Bruzzone, F. (2008). Los topos. Buenos Aires: Mondadori.

Bruzzone, F. (2014). 76. Un clásico + dos nuevos cuentos. Buenos Aires: Momofuku.

Burucúa, J. E. (2003a). Historia, arte y cultura. De Aby Warburg a Carlo Guinzburg. Buenos Aires: FCE.

Burucúa, J. E. (2003b). Entrevista: "El señor de las imágenes". Suplemento Radar de Página/12, 9 de noviembre de 2003.

Da Silva Catela, L. (2012). "Re-velar el horror. Fotografía, archivos y memoria frente a la desaparición de personas". En I. Piper \& B. Rojas (Eds.), en Memorias, Historia y Derechos Humanos (pp. 157-75). Santiago de Chile: Programa Domeyko Sociedad y Equidad, Universidad de Chile.

Cueto Rúa, S. (2008). Nacimos en su lucha, viven en la nuestra. Identidad, justicia y memoria en la agrupación HIJOS-La Plata. La Plata: Memoria Académica, Fahce-UNLP. En línea.

Sigmund F. (1993). "Duelo y melancolía”, Obras Completas, Tomo XIV. Buenos Aires: Amorrortu Editores.

Gatti, G. (2011). Identidades desaparecidas. Peleas por el sentido de los mundos de la desaparición forzada. Buenos Aires: Prometeo Libros.

Grüner, E. (2008). “La invisibilidad estratégica, o la redención política de los vivos”, en Longoni, A. y G. A. Bruzzone (comp.) (2008). El Siluetazo Buenos Aires: Adriana Hidalgo editora, pp. 285-308.

Kordon, D. y Edelman, L. (2007). Por-venires de la memoria: efectos psicológicos multigeneracionales de la represión de la dictadura: hijos de desaparecidos. Buenos Aires: Madres de Plaza de Mayo.

Laclau, E. (2005). La Razón Populista, Buenos Aires: FCE. 
Mouffe, Ch. (2015). La política popular. Entrevista pública a Chantal Mouffe. Facultad Libre de Rosario. En línea.

Longoni, A y Bruzzone G. A. (comp.) (2008). "Introducción" a El Siluetazo Buenos Aires: Adriana Hidalgo editora, pp. 5-60.

Oberti, A. (2015). Las revolucionarias. Militancia, vida cotidiana y afectividad en los setenta, Buenos Aires: Edhasa.

Schindel, E. (2008). "Siluetas, rostros y escraches. Memoria y performance alrededor del movimiento de derechos humanos", en Longoni, A. y Bruzzone G. A. (comp.) (2008). El Siluetazo Buenos Aires: Adriana Hidalgo editora, pp. 411425 . 